\title{
Assessment of habitat change on bird diversity and bird-habitat network of a Coral Island, South China Sea
}

\author{
Yingcan Li, Zhiwen Chen, Chao Peng, Guangchuan Huang, Hongyu Niu and Hongmao Zhang* (i)
}

\begin{abstract}
Background: Understanding how island ecosystems change across habitats is a major challenge in ecological conservation under the conditions of habitat degradation. According to a 2-year investigation on Dong Island of the Paracel Islands, South China Sea, we assessed the roles of different habitats at the species level and community level of birds using topological and network analysis.

Results: In addition to the thousands of Sula sula (a large-sized arboreal seabird) inhabiting the forests, there were 56 other bird species were recorded, representing 23 families and 12 orders, ranging in habitats of wetlands, forests, shrublands, grasslands, and/or beaches. The bird-habitat network had high nestedness, and bird species showed obvious clustering distribution. Integrated topological and network analysis showed that wetlands had a high contribution to species diversity and network structure, and it was a cluster center of migrant birds. Forests and grasslands were species hub and connector respectively, and forests were also the key habitat for residents. Beaches and shrublands were peripherals. The loss of wetlands and forests will result in a sharp reduction of species richness, and even make the $S$. sula, and most of the resident birds, become locally extinct.
\end{abstract}

Conclusions: These results suggest that the wetland and forest habitats on the focal island are key important for migrant birds and resident birds respectively, and therefore much more attention should be paid to conservation of the focal island ecosystems.

Keywords: Habitat roles, Birds, Bird-habitat network, Tropical coral island, Conservation

\section{Background}

Oceanic islands are vital to the maintenance of biodiversity of the oceanic ecosystem because they serve as transfer stations for migrant birds and marine mammals, and have a great contribution to freshwater protection and local climate regulation $[5,10,29,55,56]$. However, oceanic island ecosystems have unique vulnerabilities due to their special geographical location, isolation, limited area, and other inherent factors [18]. In recent decades, the oceanic island ecosystems have been undergoing

${ }^{*}$ Correspondence: zhanghm@mail.ccnu.edu.cn

Institute of Evolution and Ecology, School of Life Sciences, Central China

Normal University, Wuhan 430079, Hubei, China degradation due to serious anthropogenic disturbance, alien species invasion, and global climate changes [10, 24, $30,42,52]$. Therefore, island conservation and restoration have become a worldwide concern $[54,56]$.

Under the influence of natural and anthropogenic factors, island ecosystems are experiencing the shrinkage or loss of habitats, the reduction or extinction of species in these corresponding habitats, and further the degradation of ecosystem function $[14,54,56]$. Oceanic islands generally represent global biodiversity hotspots harboring a high number of endemic and rare species prone to extinction [13]. Endemic species on islands often have a narrow distribution range and few available habitat types, and therefore are incapable of adapting to anthropogenic 
habitats under the conditions of land-use changes [54]. Thus, in order to protect these diverse and fragile island ecosystems, impacts of habitat loss on animal-habitat network structure need to be better understood.

In ecological networks, responses to nodes loss and how network properties affect extinction patterns have been widely concerned in recent years [8, 22, 23, 41]. Complex networks are generally considered error resistant, however, losing a few critical nodes might make these networks extremely to be vulnerable to attack [3]. From this point of view, by combining topology and network analysis, we can predict and evaluate robustness and structure of an island ecological network, and define the important habitat nodes as the major interactors that have many links to species. Their disruption may break relationships among sets of species, and therefore destroy ecosystem integrity and function.

Birds play a crucial role in marine island ecosystems, such as pollination [36, 53], seed dispersal $[17,20]$, and soil formation $[1,59]$. Therefore, birds are often used as indicators in island ecosystems [26]. As the unique semiclosed environments, islands affect bird speciation and diversity according to their area, primary productivity, average annual temperature, distance to the mainland, and geological age $[19,35,37,56,57]$. The differences in habitat with respect to geographical location, vegetation type and resource are considered to affect the number and abundance of bird species [31, 44]. Wetlands on an island provide food, shelter, and stopover sites that allow birds to make migratory journeys [25], and the area of forest cover on an island is beneficial for the persistence of local bird species [49]. Therefore, bird-habitat network is an important indicator of the ecological function and health of the marine island ecosystems.

China's Paracel Islands are located in the midwest part of the South China Sea, consisting of 32 islands, reefs, sandbanks, and shoals. These islands are rich in natural resources and inhabited by many species of birds, and therefore have immeasurable ecological and economic value $[15,16]$. Although a part of the islands has been under the administration of nature reserves, the Paracel Islands are undergoing habitat degradation caused by invasive species and anthropogenic disturbance in recent years [38]. However, it is difficult to make decisions for ecological-based restoration and conservation to these islands due to the effects of habitat change on animal diversity and animal-habitat interactions are not fully known.

Dong Island is a typical island with continuous natural vegetation and mild disturbance of the Paracel Islands. From the center to the edge of Dong Island, the landcovers of forests, wetlands, shrublands, grasslands, and beaches are distributed sequentially but distichously between every two of them [46]. In the previous studies in 1974 and 2005, 43 and 55 bird species were recorded separately on the Paracel Islands. These birds are mainly migrant species (33 species, $76.74 \%$ in 1974, and 38 species, $69.09 \%$ in 2005), and usually utilize several specific habitat types (e.g., wetlands and forests) [33, 43]. Here, we used topological analysis to analyze the structure of bird-habitat network on Dong Island. We wanted to evaluate the role of nodes and habitats at both species and network levels. Probable effects of loss of each habitat type on bird species were assessed by removing habitats respectively and reanalyzing the bird-habitat networks. According to habitats' conditions and historical data of bird composition on Dong Island, we hypothesized that (1) the bird community on Dong Island showed a clustering distribution, in that different migrant types had different clustering habitats; and (2) wetlands were of key importance for migrant birds, whereas forests were crucially important for resident birds, and these two habitats were key factors for the network structure. These results would be helpful to understand the ecological function and dynamic of island ecosystems, and to guide the planning of island ecosystems' restoration and conservation.

\section{Results}

\section{Bird diversity and bird-habitat network structure}

During the two experimental years, thousands of S. sula and a total of 1513 individuals of other species were recorded, belonging to 57 species, 23 families, and 12 orders (Additional file 1: Table S1). Among them, 20 species were resident birds (35.1\%) and 37 species were migrant birds (64.9\%). There were 103 links between birds and habitats, including 36 species in the wetlands, 22 species in the forests, 19 species in the grasslands, 17 species in the beaches, and nine species in the shrublands. Correlation analysis showed that species number has no significant correlation with habitat size $(P=0.88)$. The bird-habitat network exhibited low modularity $(\mathrm{M}$ (Modularity) $=0.33)$, high nestedness (NODF (Nestedness metric based on the Overlap and Decreasing Fill $)=42.79$ ), and moderate connectance $(\mathrm{C}$ (Connectance $)=0.36)$ (Fig. 1).

Birds' preference for habitats varied greatly on Dong Island, for instance, $63.2 \%$ of bird species were observed in the wetlands, while only $15.8 \%$ of bird species were observed in the shrublands (Table 1). Species number was highest in the wetlands and then decreased in the order of forests, grasslands, beaches, and shrublands. The Shannon-Wiener diversity index was highest in the wetlands, followed by the beaches, grasslands, shrublands, and forests. A greater proportion of migrant birds occurred in the wetlands and beaches than in the other habitats, while there were more resident birds in the 


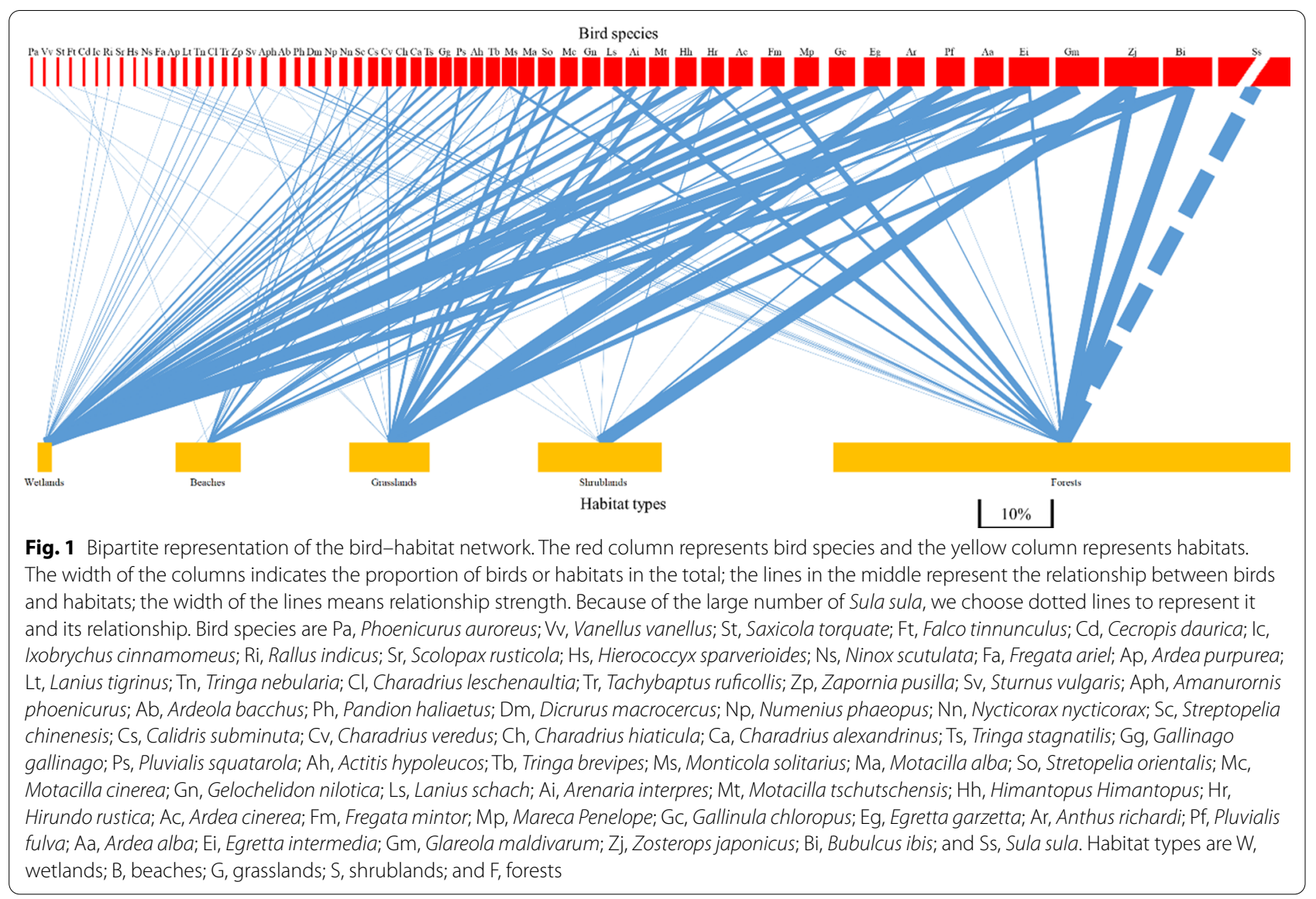

Table 1 Bird species diversity and the basic parameters of bird-habitat network in each habitat on Dong Island, South China Sea

\begin{tabular}{llllll}
\hline & Wetlands & Forests & Beaches & Grasslands & Shrublands \\
\hline Bird species (\%) & $36(63.16)$ & $22(38.60)$ & $17(29.82)$ & $19(33.33)$ & $9(15.79)$ \\
Resident birds (\%) & $12(60)$ & $13(65)$ & $5(25)$ & $13(65)$ & $5(25)$ \\
Migrant birds (\%) & $24(64.86)$ & $9(24.32)$ & $12(32.43)$ & $6(16.22)$ & $4(10.81)$ \\
Shannon-Wiener diversity index & 2.86 & 0.41 & 2.43 & 2.27 & 0.77 \\
Pielou uniformity index & 0.80 & 0.13 & 0.86 & 12.27 & 0.26 \\
Habitat strength & 22.78 & 12.87 & 6.39 & 0.59 & 0.5 \\
Interaction asymmetry & 0.61 & 0.54 & 0.32 & 0.5 & 1 \\
Nested rank & 0 & 0.25 & 0.75 & 0.37 & 0.88 \\
Specificity index & 0.25 & 0.92 & 0.32 & & \\
\hline
\end{tabular}

forests than in other habitats. Pielou uniformity index was lower in the forests and shrublands than in the other habitats (Table 1).

For species-level network parameters in the wetlands, habitat strength and interaction asymmetry were the highest, and nested rank and specificity index were the lowest (Table 1), suggesting that the wetlands were a key node for bird species and networks, and had the highest contribution to both the bird community and network structure. In the forests and grasslands, habitat strength and interaction asymmetry were relatively high, while nested rank were medium or low, suggesting that these habitats had a relatively high contribution to bird species and network structure. In the beaches and shrublands, the low level of habitat strength and interaction asymmetry, and a high nested rank indicated a relatively low status in the network and limited species contribution. Shrublands and forests had the highest specificity index 
due to the few numbers of bird species and the largest number of S. sula individuals respectively.

The similarity trees of resident birds, migrant birds and in total showed insignificant difference among habitats (Fig. 2). The similarity sequences of total bird species and migrant bird species were the same, for example, the shrublands had the closest similarity with the beach, and the most dissimilar with the wetlands. While in the similarity tree of resident bird species, the closest and furthest similarity from the shrubland were those of the grasslands and forests, respectively.

In the topological approach, the sequence removing the smallest habitat shows the lowest robustness (Additional file 1: Fig. S1). First, the bird-habitat network was less robust to the sequences removing the most connected and the smallest habitat as compared to the random sequence. Second, the bird-habitat network was more robust against the sequences removing the least connected and the biggest habitat than the random sequence.

\section{Effects of presumed habitat loss}

We used the topological method to simulate habitat loss in the network (Fig. 3). Bird species on Dong Island were greatly reduced with the increase of habitat loss of the wetlands and forests (Fig. 4a, Additional file 1: Fig. S2a), indicating many species only utilized these habitats. Shannon-Wiener diversity of birds increased greatly with the increasing percentage of habitat loss of the forests, while the index decreased with the loss of the wetlands, grasslands, or beaches when S. sula was excluded (Fig. 4b, Additional file 1: Fig. S2b). Pielou uniformity index increased sharply with increased loss of the forests, while the index decreased with the loss of the wetlands or grasslands when S. sula was excluded (Fig. 4c, Additional file 1: Fig. S2c). Simulation of species parameters indicated that the birds mainly utilized the habitats of the wetlands, grasslands, and beaches, while the shrublands and beaches had a relatively low population of birds.

For network structure, removal of each habitat had a similar effect on connectance (Fig. 4d, Additional file 1: Fig. S2d), while differed on modularity and nesting. Removal of the forests caused an increase of modularity of the bird-habitat network. In contrast, when S. sula were excluded, removal of the grasslands caused a great reduction of modularity, and removal of the beaches or forests caused a small increase and decrease, respectively, and removal of the wetlands and shrublands had little effects on the modularity of the network (Fig. 4e, Additional file 1: Fig. S2e). Removal of the forests caused the network to be more nested, while removal of the wetlands caused a great reduction of nestedness. Meanwhile, removal of the beaches or grasslands caused a little reduction of nestedness, whereas, removal of the shrublands caused a little effect on nestedness (Fig. 4f, Additional file 1: Fig. S2f).

For migrant birds, removal of the wetlands caused a loss of 12 species (32.4\%), and then decreased with the order of the grasslands (three species, $8.1 \%$ ), beaches (two species, 5.4\%), forests (two species, 5.4\%) and shrublands (one species, 2.7\%) (Fig. 4g, Additional file 1: Fig. S2g). For resident species, removal of the forests caused a loss of five species (25.0\%), removal of the wetlands (two species, $10.0 \%$ ) or beaches (one species, $5.0 \%$ ) caused light effects, while removal of the grasslands or shrublands

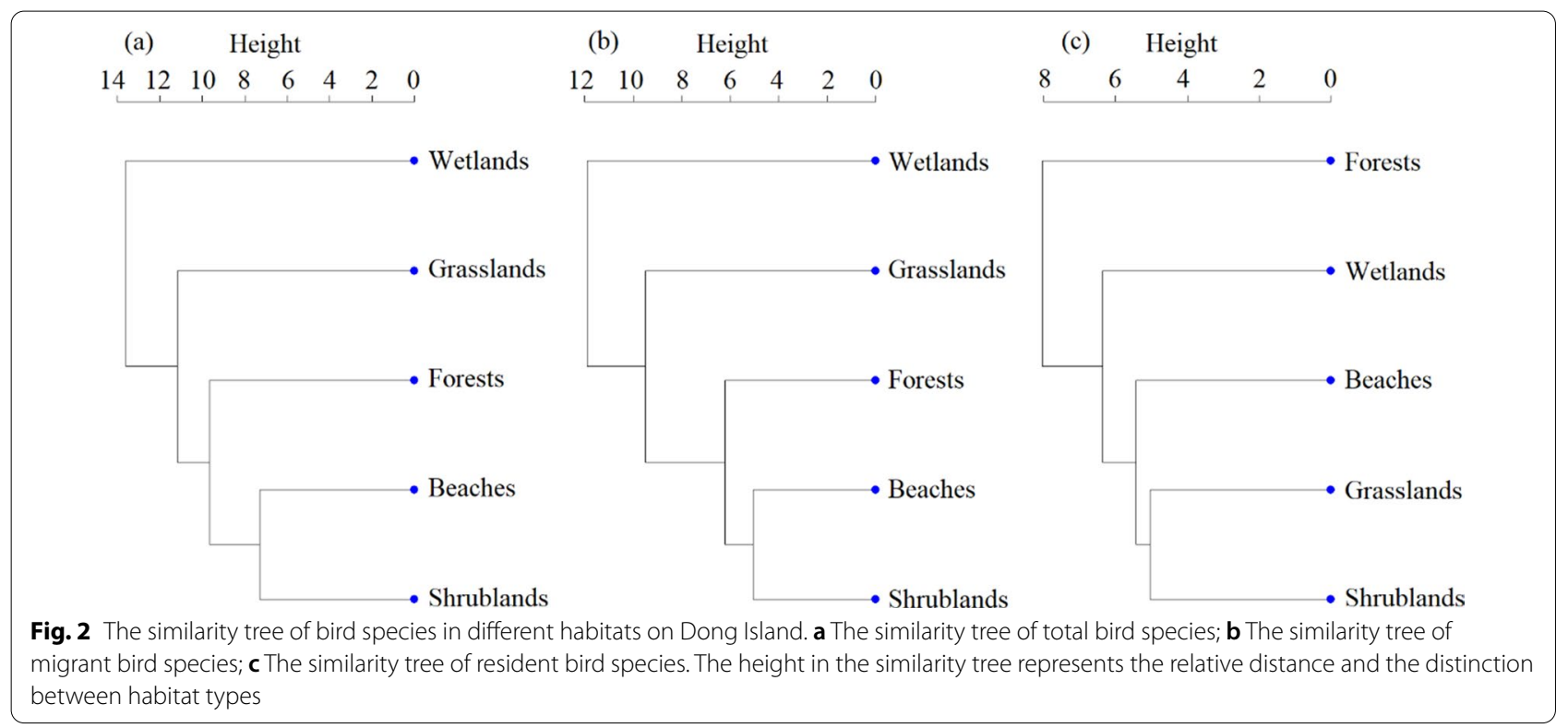




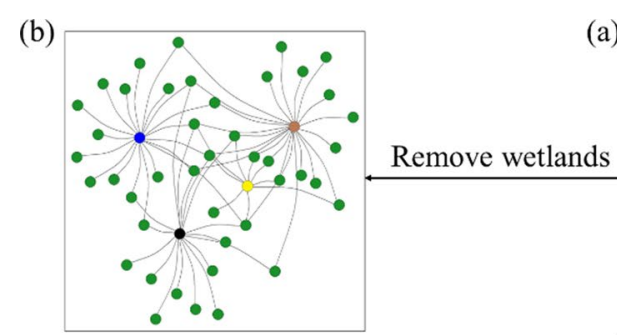

(a)

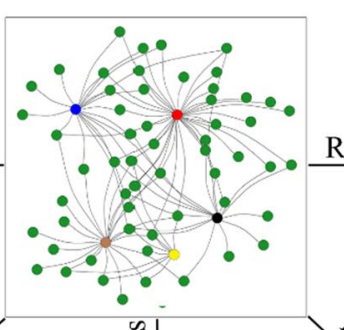

(f)

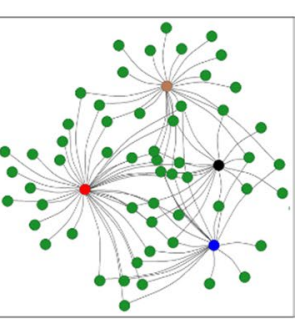

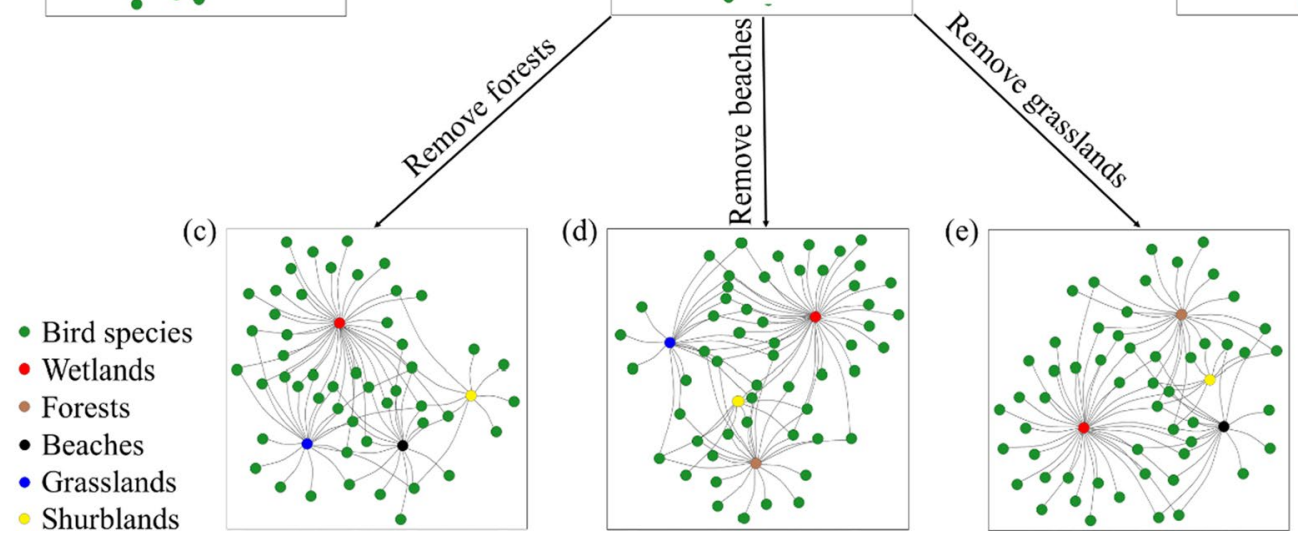

Fig. 3 Bipartite representation of the bird-habitat network on Dong Island, South China Sea. a The structure of the network including all birds and habitats. $\mathbf{b}$ The structure of the network when wetlands were removed. $\mathbf{c}$ The structure of the network when forests were removed. $\mathbf{d}$ The structure of the network when beaches were removed. $\mathbf{e}$ The structure of the network when grasslands were removed. $\mathbf{f}$ The structure of the network when shrublands were removed. The nodes represent habitat types and bird species, the lines represent the bird species distribution in the habitats

had no effects on resident bird species (Fig. 4h, Additional file 1: Fig. S2h).

\section{Discussions}

Our results suggest that bird species showed clustering distribution and were not related to habitat area, and different habitats played different roles in bird-habitat network structure, supporting our previous hypothesis 1 : the bird community on Dong Island showed a clustering distribution, in that different migrant types had different clustering habitats. Among all of the habitats, removal of grasslands reduced modularity of the network to the greatest extent. Nestedness of the network decreased greatly when the wetlands were removed, while it increased by the loss of the forests. Migrant birds primarily utilized the wetlands, and resident birds predominantly inhabited the forests. As hypothesis 2 predicted, both the wetlands and forests provide a great contribution to the structure and biodiversity of the bird-habitat network on Dong Island, and therefore they should receive more attention in conservation.

Compared to the other islands of the study area, Dong Island has a relatively high species richness and diversity of birds, showing a clustered distribution unrelated to habitats' area. Many species only utilized one or two habitats. For example, Egretta intermedia were common in the wetlands, S. sula, Bubulcus ibis mainly utilized the forests, Zosterops japonicus were mainly distributed in the shrublands, Glareola maldivarum were easily found in the grasslands, and Ardea alba were common to see on the beaches. On Dong Island, Pan [43] reports there are 42 species of birds (19 families, 10 orders, 12 resident birds and 30 migrant birds). Cao et al. [15] report there are more than 35,500 pairs of $S$. sula inhabiting the forests on Dong Island. Compared to these studies, our results suggest that species richness and diversity of birds have a slight increase, and the structure of the bird community changed accordingly. With the reduction of anthropogenic disturbance and restoration of vegetation (e.g., planting trees and grass), habitats on Dong Island are being made more suitable for bird breeding [15]. Compared to the previous studies [43], species of Coraciiformes, Ciconiiformes, Accipitridae, and Cettiidae were not recorded, and species of Aniseriformes, Podicipediformes, Columbiformes, Cuculiformes, Strigiformes, Pandionidae, Dicruridae, Laniidae, Sturnidae, and Muscicapidae were firstly recorded this time. The smallest wetland contained the highest species richness, while the shrublands, the second-largest habitat, had the least number of species, and the forests contained almost all of $S$. sula and other resident birds. In contrast to the species-area relationship in that species richness is positively correlated to habitat area size, the non-uniform distribution of birds on Dong Island might be caused by 
(a)

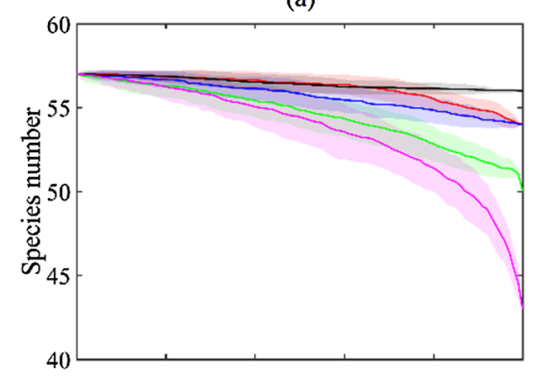

(d)

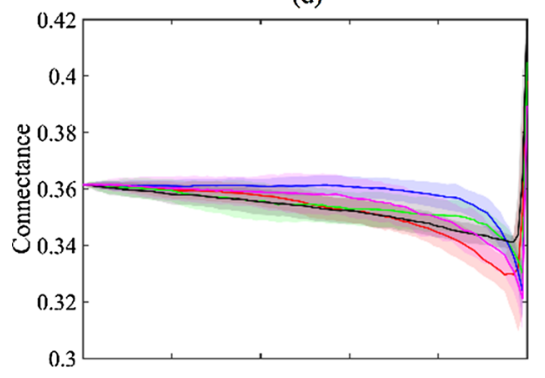

(g)

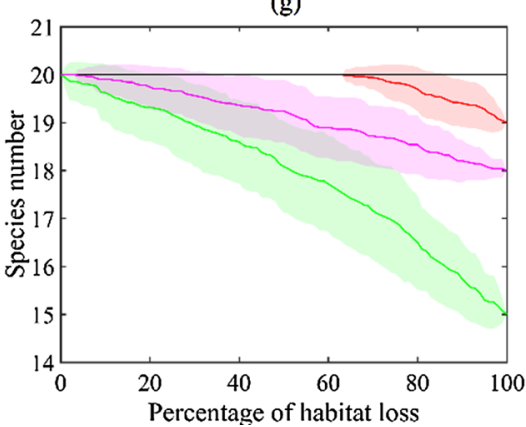

(b)

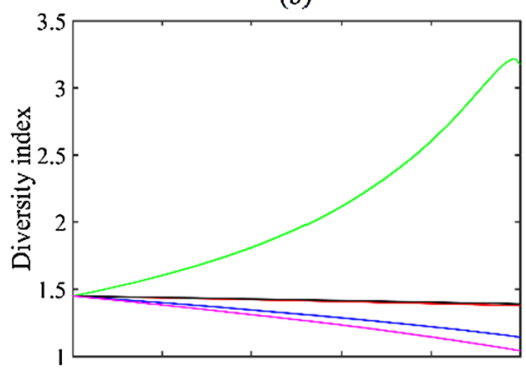

(e)

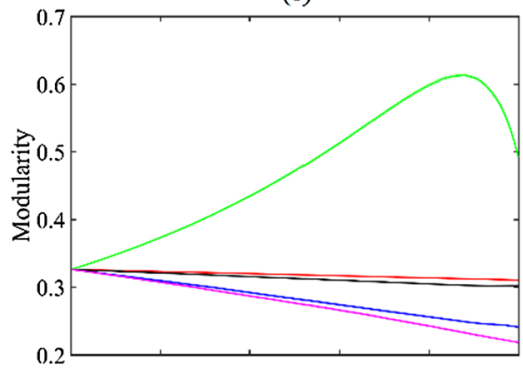

(h)

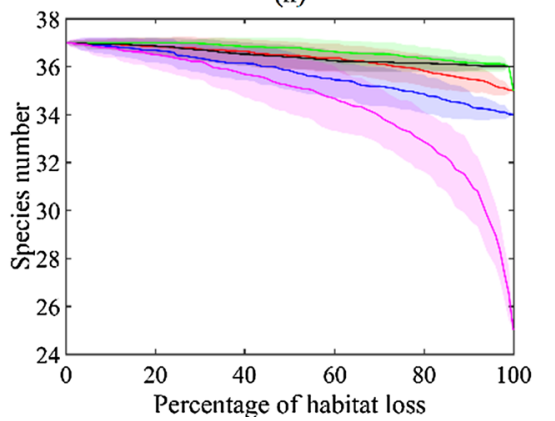

(c)

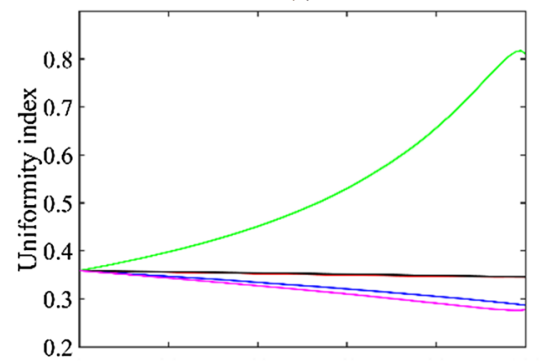

(f)

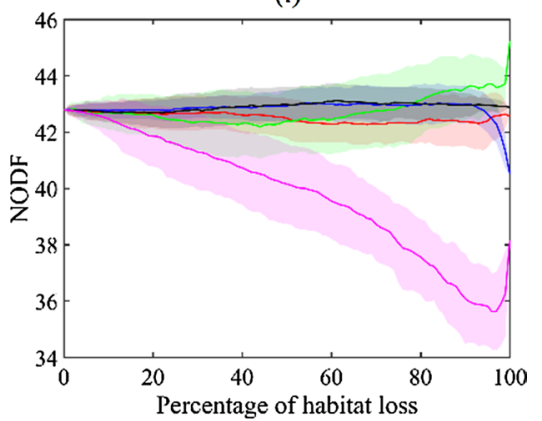

- Beaches

- Forests

- Grasslands

- Shrublands

- Wetlands

Fig. 4 Effects of presumed habitat loss on the bird diversity and bird-habitat network structure on Dong Island, South China Sea. a species number; $\mathbf{b}$ Shannon-Wiener diversity index; c Pielou uniformity index; $\mathbf{d}$ Connectance of the bird-habitat network; e Modularity of the bird-habitat network; $\mathbf{f}$ NODF of the bird-habitat network; $\mathbf{g}$ Species number of resident birds; $\mathbf{h}$ Species number of migrant birds

the unique food availability, shelter, nest sites, and species interactions in each habitat $[28,58]$.

The similarity between habitats was relatively low, and the similarity tree of total bird species was dominated by migrant birds (Fig. 2). There are obvious differences in similarity tree between migrant and resident bird community. The different patterns represent each resident type has its own habitat preference. The migrant bird community is mainly consisted of wading birds (such as shorebirds and egrets), and their typical habitat is wetlands such as tidal flats and swamps. The resident bird community is mainly consisted of songbirds, wading birds and raptors, they prefer habitats that provide safe shelter or food resources such as insects or plant seeds.

Loss of habitat on islands usually leads to threatened and extinction of endemic species, as well as simplification and fragility of ecological networks [14, 42]. Our results showed that different types of habitat played various roles in species and network levels, and effects of habitat loss on species and network structure had been predicted. Loss of wetlands had the greatest impact on diversity index, species number, and uniformity index, and greatly reduced nestedness in the bird-habitat network, which would cause serious loss of biodiversity and simplification of the ecological network. This loss of biodiversity occurs because, on such an oceanic coral island, the wetland habitat serves as a community hub, and typically supports a variety of biota, many of which are wetland specific species, by providing fresh water, improving water quality and providing additional habitat structure with its plants $[6,60]$. Loss of the grasslands had a moderate impact on diversity index, species number, and greatly reduced uniformity index and modularity of the network, which would cause moderate loss of biodiversity but serious network instability. Considering S. sula, loss of the forests greatly changed the diversity, 
uniformity, and modularity. In contrast, it had a serious impact on species number and slight incremental addition of nestedness when $S$. sula was excluded. Therefore, grasslands indicate that it is a connector, while the forests present a species hub. As for the shrublands or beaches, their removal had little impact on both diversity and network structure. Such peripherals contributed little to the entire ecosystem and had little impact on network structure or species diversity.

China's Paracel Islands are located in the East AsianAustralasian Flyway (EAAF), one of the four globally recognized flyways for migratory birds [12]. Birds in the EAAF are facing complex and formidable threats, and habitat loss is a serious problem [47]. On Dong Island, the wetlands contain the maximum and most unique migrant species, and its loss would seriously affect the migrant richness and ecological function. Forests are not only the key habitat for the resident birds of Dong Island but also provide the only breeding ground and habitat for the largest breeding population of the S. sula in the Western Pacific [15]. Thus, the forests on Dong Island is crucially important and, therefore, is integral to conservation.

\section{Conclusions}

Dong Island had a relatively high richness of birds and habitats, and the birds tended to cluster their distribution and had high diversity in some narrow habitats (e.g., wetlands and grasslands). The wetlands were a community hub of the bird-habitat network, the forests and grasslands were species hubs and connectors respectively, and the beaches and shrublands were peripherals. The wetlands were crucial for migrant species, while the forests were essential for resident species, especially for $S$. sula, the largest breeding population in the Western Pacific. Our study on bird-habitat network provides a possibility to examine community-driven, robust patterns of habitat loss in tropical coral island ecosystems, and may be applicable to other types of ecological networks. The network responses of simulated habitat loss may provide novel insights into its stability from a structural perspective, which helps to explain the role of habitats in the island ecosystems, and highlights that integration of topology and network analysis is practical to assess conservation objectives.

\section{Methods}

\section{Study site}

We conducted this study on Dong Island of the Paracel Islands, China. The area is $171 \mathrm{ha}$, making it the secondlargest island in the Paracel Islands. The elevation is about 3-6 m, and the highest point is $6.7 \mathrm{~m}$. The shoreline is $6.12 \mathrm{~km}$ in length, and the distance between Dong
Island and the mainland of China is about $337 \mathrm{~km}$ [48]. The Paracel Islands have a tropical monsoon climate, with a mean annual temperature of $26{ }^{\circ} \mathrm{C}$, mean annual precipitation of $1500 \mathrm{~mm}$, mean annual sunlight of $2900 \mathrm{~h}$, and mean annual relative humidity of $81 \%$. The dry season is from December to May, and the rainy season is from June to November, accounting for $87 \%$ of the annual rainfall [39]. The island is under state protection and maintains the best natural vegetation in the Paracel Islands, but the habitats are still undergoing degradation due to the invasion of alien species (e.g., Chromolaena odorata, Sphagneticola lobata, Rattus flavipectus), garbage accumulation from ocean currents, global climate change, and other threats, which puts high pressure on the island ecosystem $[15,46]$.

\section{Habitat type}

There are five main habitat types on Dong Island. The largest vegetation type is broad-leaved evergreen forests, which have an area of 99 ha and greatly distributed in the core of the island. The common trees are Ceodes grandis and Guettarda speciose, with 4-10 m height, 70-80\% canopy cover. There are very few undergrowth vegetations under forests. The second largest vegetation type, shrublands, is about 20.2 ha, mainly distributed along the coast of the island. The shrubs are $1-2.5 \mathrm{~m}$ in height and $55-75 \%$ in coverage, and dominated by Scaevola sericea and Messerschmidia argentea. The grasslands are about 19.0 ha in area size, distributed on the beaches of the high tide line of the coastal front and in the open lands of the island, dominated by herbaceous species Ipomoea pescaprae, liana species Tridax procumbens, Portulaca oleracea, and Zoysia matrella. The beaches are about 11.2 ha, distributed on the edge of the island, and support growth of a few salt-tolerant plants. Whereas the wetland is a naturally brackish-water lake and the shallow-water areas around it, about 2.2 ha in size, located at the south of the island, and dominated by two species of limnophyte, Paspalum longifolium and Sesuvium portulacastrum.

\section{Bird survey}

Four line-transects were sampled for bird survey on the whole island. Each transect was $800-1000 \mathrm{~m}$ in length, passed through all types of habitats, and the sampled areas covered more than $80 \%$ of the island. In each transect, five sites with an interval of 150-200 m were selected for point counts, and the location of each site was recorded by a GPS of mobile phone (Huawei Mate30 Pro + , HUAWEI TECHNOLOGIES CO., LTD., China).

Each transect was repeatedly investigated at least 10 times in each season (dry and rainy season) from May 2018 to December 2019. Field observations were conducted at $0600-0900 \mathrm{~h}$ and $1600-1900 \mathrm{~h}$ on each 
survey day. For each survey, two people walked along each transect at a speed of $2-3 \mathrm{~km} / \mathrm{h}$ to observe birds using binoculars (Kowa, $10 \times 42$, made in Japan) and telephoto cameras (Nikon P900s, made in Japan). A total of 20-30 min was spent for point count at each site. For each observation, bird species, the number of individuals, and their habitats were recorded. Birds were identified and classified according to A Field Guide to the Birds of China [40], and A Checklist on the Classification and Distribution of the Birds of China (3rd edition) [61].

\section{Bird-habitat networks}

We used the following parameters to characterize bird diversity and bird-habitat network through bipartite package [21] in R 3.4.2 [45]:

(1) Richness, the number of bird species;

(2) Shannon-Wiener diversity index and Pielou uniformity index, parameters to measure abundance and heterogeneity, were mainly used in the diversity characteristics of birds [32],

(3) Connectance $(C)$, the proportion of realized interactions out of those possible in the network [22],

(4) Nestedness (NODF, Nestedness metric based on the Overlap and Decreasing Fill), which describes a pattern in which birds in habitats with few bird species were subsets of those in habitats with many bird species [4],

(5) Modularity (M), refers to subsets (module) of closely interacting species, which has relatively little or no interaction with other subsets [27],

(6) Habitat strength, which refers to the sum of the action intensity of a particular habitat on species [7],

(7) Nested rank, which refers to the level of a network nested matrix, with the lower the value, the higher the universality, and vice versa [2],

(8) Specificity index, also known as specialization, is used to measure the degree of specialization, the more species interact with it, the lower the specificity index [11],

(9) Interaction asymmetry, refers to the species asymmetry of interaction; positive value represents that a particular habitat has greater dependence or influence on species, and a negative value represents that a particular habitat is dependent or influenced by species $[7,11]$.

Forms of computation of these parameters were presented as supplement methods (Additional file 1: additional methods).

We used ANOVA and correlation analysis for data processing, and used hierarchical clustering analysis to construct similarity trees. All data analyses were performed in R 3.4.2 [45].

\section{Simulation of habitat loss}

A weighted bird-habitat network was described by a type of adjacency matrix called flux matrix A [9]. Each nonzero element $\mathrm{A}_{[i, j]}$ represents the number of bird $j$ visiting habitat $i$. Column $j$ represents the chosen habitats of bird species $i$. For simplicity, we assumed that birds cannot switch from one type of habitat to another after habitat loss [51]. In the binary extinction scenario, a bird species $j$ goes extinct when the normalized column sum of the $j$ column, that is, species $j$ goes extinct when there is a lack of available habitat [22, 23, 50]. We performed simulations in which a certain percentage of habitat was randomly removed at each step and the number of secondary extinctions was recorded. The procedure was repeated until all the nodes were lost.

In the simulation of the impact of habitat loss on birdhabitat network structure, where secondary extinctions occur when a species was left without any exploitable resources [34]. The extinction threshold was not considered because birds on oceanic islands have a strong dispersal capacity [8].

Because there are more than 35,500 pairs of $S$. sula inhabit the forest on Dong Island [15], which concealed the effects of habitat loss when using the Shannon-Wiener diversity, Pielou uniformity, and modularity analyses, we repeated these analyses by excluding $S$. sula.

\section{Abbreviations}

C: Connectance; NODF: Nestedness metric based on the overlap and decreasing fill; M: Modularity.

\section{Supplementary Information}

The online version contains supplementary material available at https://doi. org/10.1186/s12862-021-01865-y.

Additional file 1: Table S1. Bird species on Dong Island, South China Sea. Fig. S1. The robustness to habitat loss in the topological approach. On the $y$-axis is robustness measured as R50. Each box plot contains the R50 values from the 50 repeated simulations. Lower case letters above the box plots denote significantly different sequences (different letters) in the ANOVA at the 0.05 level. Fig. S2. Effects of presumed habitat loss on the bird diversity and bird-habitat network structure on Dong Island, South China Sea when Sula sula was excluded. (a), species number; (b), ShannonWiener diversity index; (c), Pielou uniformity index; (d), Connectance of the bird-habitat network; (e), Modularity of the bird-habitat network; ( $f$ ), NODF of the bird-habitat network; (g), Species number of resident birds; (h), Species number of migrant birds.

Acknowledgements

We thank H. Ren, S. Jian, Z. liu, H. Cai, S. Tong, and Y. Huang for assistance with field works, and Jacob Wickham for English editing, and J. Liao for helpful conversation about topological analysis. This study was supported by the National Natural Science Foundation of China (NSFC) and Guangdong Province Union Funds (U1701246), and partially supported by NSFC (31772471). We thank all 
of the anonymous reviewers for delivering constructive and thorough reviews that greatly improved the manuscript at all levels.

\section{Authors' contributions}

ZH and LY contributed conception and design of the study. LY, CZ, PC, ZH and HG collected the data. LY wrote the first draft of the manuscript. $\mathrm{ZH}, \mathrm{NH}$, and LY contributed to the analysis of the data, and manuscript revision. All authors read and approved the final manuscript.

\section{Funding}

This study was supported by the National Natural Science Foundation of China (NSFC) and Guangdong Province Union Funds (U1701246), and partially supported by NSFC (31772471). The funding bodies played no role in the design of the study and collection, analysis, and interpretation of data and in writing the manuscript.

\section{Availability of data and materials}

Data sources for bird species and bird-habitat relationship for our study can be found in Additional file 1: Table S1.

\section{Declarations}

\section{Ethics approval and consent to participate}

Ethical review and approval were not required for the animal study because in this study, birds were only observed for a long-distance and no direct or indirect interference to animals. The experiments presented here comply with current Chinese law.

\section{Consent for publication}

Not applicable.

\section{Competing interests}

The authors declare that the research was conducted in the absence of any commercial or financial relationships that could be construed as a potential conflict of interest.

Received: 28 January 2021 Accepted: 21 June 2021

Published online: 06 July 2021

\section{References}

1. Abakumov E. Content of available forms of nitrogen, potassium and phosphorus in ornithogenic and other soils of the Fildes Peninsula (King George Island, Western Antarctica). Biol Commun. 2018;63:109-16. https://doi.org/10.21638/spbu03.2018.203.

2. Alarcón R, Waser NM, Ollerton J. Year-to-year variation in the topology of a plant-pollinator interaction network. Oikos. 2008;117:1796-807. https:// doi.org/10.1111/j.0030-1299.2008.16987.x.

3. Albert $\mathrm{R}$, Jeong $\mathrm{H}$, Barabasi AL. Error and attack tolerance of complex networks. Nature. 2000;406:378-82. https://doi.org/10.1038/35019019.

4. Almeida-Neto M, Guimaraes P, Paulo R, Guimarães JR, Loyola RD, Ulrich W. A consistent metric for nestedness analysis in ecological systems: reconciling concept and measurement. Oikos. 2008;117:1227-39. https:// doi.org/10.1111/j.0030-1299.2008.16644.x.

5. Anthony SS, Peterson FL, Mackenzie FT, Hamlin SN. Geohydrology of the Laura freshwater lens, Majuro Atoll: a hydrogeochemical approach. Geol Soc Am Bull. 1989;101:1066-75. https://doi.org/10.1130/0016-7606(1989) 101\%3c1066:GOTLFW\%3e2.3.CO;2.

6. Barbier EB, Hacker SD, Kennedy C, Koch EW, Stier AC, Silliman BR. The value of estuarine and coastal ecosystem services. Ecol Monogr. 2011;81:169-93. https://doi.org/10.1890/10-1510.1.

7. Bascompte J, Jordano P, Olesen J. Asymmetric coevolutionary networks facilitate biodiversity maintenance. Science. 2006;312:431-3. https://doi. org/10.1126/science.1123412.

8. Bellingeri M, Vincenzi S. Robustness of empirical food webs with varying consumer's sensitivities to loss of resources. J Theor Biol. 2013;333:18-26. https://doi.org/10.1016/j.jtbi.2013.04.033.
9. Bersier L, Banasék-Richter C, Cattin M. Quantitative descriptors of foodweb matrices. Ecology. 2002;83:2394-407. https://doi.org/10.2307/30718 01.

10. Blackburn TM, Cassey P, Duncan RP, Evans KL, Gaston KJ. Avian extinction and mammalian introductions on oceanic islands. Science. 2004;305:1955-8. https://doi.org/10.1126/science.1101617.

11. Blüthgen N, Menzel F, Blüthfen N. Measuring specialization in species interaction networks. BMC Ecol. 2006;6:9. https://doi.org/10.1186/ 1472-6785-6-9.

12. Boere GC, Stroud DA. The flyway concept: what it is and what it isn't. In: Boere GC, Galbraith CA, Stroud DA, editors. Waterbirds around the world. Edinburgh: The Stationery Office; 2006. p. 40-7.

13. Brooks TM, Mittermeier RA, Mittermeier CG, Fonseca GABD, Rylands AB, Konstant WR, Flick P, Pilgrim J, Oldfield S, Magin G, Hilton-Talor C. Habitat loss and extinction in the hotspots of biodiversity. Conserv Biol. 2002;16:909-23. https://doi.org/10.2307/3061167.

14. Brooks TM, Pimm SL, Collar NJ. Deforestation predicts the number of threatened birds in insular Southeast Asia. Conserv Biol. 1997;11:382-94. https://doi.org/10.1046/j.1523-1739.1997.95493.x.

15. Cao L, Pang Y, Liu N. Status of the red-footed booby on the Xisha Archipelago, South China Sea. Waterbirds. 2005;28:411-9. https://doi.org/10. 1675/1524-4695(2005)28[411:SOTRBO]2.0.CO;2.

16. Cao L, Zhang S, Shi H, Liu N. Primarily observation of breeding population of great frigate birds (Fregata minor) on Dong Island of Xisha Archipelago. Zool Res. 2003;24:457-61. https://doi.org/10.3321/j.issn:0254-5853.2003. 06.010 (in Chinese with English abstract).

17. Carpenter JK, Dave K, Elena M, O'Donnell CFJ. Introduction of mammalian seed predators and the loss of an endemic flightless bird impair seed dispersal of the New Zealand tree Elaeocarpus dentatus. Ecol Evol. 2018;8:5992-6004. https://doi.org/10.1002/ece3.4157.

18. Chi Y, Shi H, Wang Y, Guo Z, Wang E. Evaluation on island ecological vulnerability and its spatial heterogeneity. Mar Pollut Bull. 2017;125:216-41. https://doi.org/10.1016/j.marpolbul.2017.08.028.

19. Clegg SM, Degnan SM, Moritz C, Estoup A, Kikkawa J, Owens IP. Microevolution in island forms: the roles of drift and directional selection in morphological divergence of a passerine bird. Evolution. 2007;56:2090-9. https://doi.org/10.1111/j.0014-3820.2002.tb00134.x.

20. Culliney S, Pejchar L, Switzer R, Ruiz-Gutierrez V. Seed dispersal by a captive corvid: the role of the 'Alalā (Corvus hawaiiensis) in shaping Hawai'i's plant communities. Ecol Appl. 2012;22:1718-32. https://doi.org/10.1890/ 11-1613.1.

21. Dormann CF, Gruber B, Fründ J. Introducing the bipartite package: analysing ecological networks. R News. 2008;8:8-11.

22. Dunne JA, Williams RJ, Martinez ND. Network structure and biodiversity loss in food webs: robustness increases with connectance. Ecol Lett. 2002;5:558-67. https://doi.org/10.1046/j.1461-0248.2002.00354.x.

23. Dunne JA, Williams RJ, Martinez ND. Network structure and robustness of marine food webs. Mar Ecol Prog Ser. 2004;273:291-302. https://doi.org/ 10.3354/meps273291.

24. Erwin RM, Brinker DF, Watts BD, Costanzo GR, Morton DD. Islands at bay: rising seas, eroding islands, and waterbird habitat loss in Chesapeake Bay (USA). J Coast Conserv. 2011;15:51-60. https://doi.org/10.1007/ s11852-010-0119-y.

25. Ferrarini A, Celada C, Gustin M. Preserving the Mediterranean bird flyways: assessment and prioritization of 38 main wetlands under human and climate threats in Sardinia and Sicily (Italy). Sci Total Environ. 2021;751: 141556. https://doi.org/10.1016/j.scitotenv.2020.141556.

26. Furness RW, Greenwood JJD. Birds as monitors of pollutants. Netherlands, Berlin: Springer; 1993.

27. Guimerà R, Stouffer DB, Sales-Pardo M, Leicht EA, Mewman ME, Amaral LA. Origin of compartmentalization in food webs. Ecology. 2010;91:294151. https://doi.org/10.1890/09-1175.1.

28. Häkkilä M, Abrego N, Ovaskainen O, Mönkkönen M. Habitat quality is more important than matrix quality for bird communities in protected areas. Ecol Evol. 2018;8:4019-30. https://doi.org/10.1002/ece3.3923.

29. Halpern BS, Walbridge S, Selkoe KA, Kappel CV, Micheli F, D'Agrosa C, Bruno JF, Casey KS, Ebert C, Fox HE, Fujita R, Heinemann D, Lenihan HS, Madin EM, Perry MT, Selig ER, Spalding M, Steneck R, Watson R. A global map of human impact on marine ecosystems. Science. 2008;319:948-52. https://doi.org/10.1126/science.1149345. 
30. Hanski I, Meyke E, Miinala M. Deforestation and tropical insect extinction. Biol Lett. 2009;5:653-5. https://doi.org/10.1098/rsbl.2009.0457.

31. Henao-Diaz LF, Sinclair ARE. Long-term monitoring of Serengeti bird species occurrence, abundance, and habitat. Ecology. 2020;101 (2): e02919. https://doi.org/10.1002/ecy.2919.

32. Hill MO. Diversity and evenness: a unifying notation and its consequences. Ecology. 1973;54:427-32. https://doi.org/10.2307/1934352.

33. Institute of Zoology Chinese Academy of Sciences, South China Sea Institute of Oceanology, Beijing Natural History Museum (1974) The investigation reports of animals in Nanhai. Acta Zool. Sin. 20(2):113-130 (in Chinese with English abstract). CNKI:SUN:BEAR.0.1974-02-002

34. Jordán F, Scheuring I, Vida G. Species positions and extinction dynamics in simple food webs. J Theor Biol. 2002;215:441-8. https://doi.org/10. 1006/jtbi.2001.2523.

35. Kalmar A, Currie DJ. A global model of island biogeography. Glob Ecol Biogeogr. 2006;15:72-81. https://doi.org/10.1111/j.1466-822x.2006. 00205.x.

36. Kelly D, Ladley J, Robertson AW, Anderson SH, Wiser SK. Mutualisms with the wreckage of an avifauna: the status of bird pollination and fruitdispersal in New Zealand. N Zeal J Ecol. 2010;34:66-85. https://doi.org/10. 1111/j.1755-0998.2009.02796.x.

37. Kreft H, Jetz W, Mutke J, Kier G, Barthlott W. Global diversity of island floras from a macroecological perspective. Ecol Lett. 2008;11:116-27. https:// doi.org/10.1111/j.1461-0248.2007.01129.x

38. Li Y, Huang $X$, Yue W. Environmental quality and management measures in Yongxing Island of Xisha, South China Sea. Mar Environ Sci. 2004;23:503. https://doi.org/10.3969/j.issn.1007-6336.2004.01.015 (in Chinese with English abstract).

39. Ling X, Cheng X, Wang F. The survey report of the climate of island of Hainan Province. In: Lu F, Xiong S, Liu S, editors. Resource, synthetically special investigations report collections of Hainan Province. Beijing: Maritine Press; 1999. p. 24-35 (in Chinese).

40. Mackinnon J, Phillipps K, He F. A field guide to the birds of China. Changsha China: Hunan Education Press; 2000.

41. Memmott J, Waser NM, Price MV. Tolerance of pollination networks to species extinctions. Proc Biol Sci. 2004;271:2605-11. https://doi.org/10. 1098/rspb.2004.2909.

42. Otto R, Garzón-Machado V, Arco MD, Fernández-Lugo S, Nascimento LD, Oromi P, Beáz M, Ibáñez M, Alonso MR, Fernández-Palacios JM. Unpaid extinction debts for endemic plants and invertebrates as a legacy of habitat loss on oceanic islands. Divers Distrib. 2017;23:1031-41. https:// doi.org/10.1111/ddi.12590.

43. Pan Y (2005) Study on the bird community structure and species-area relationship on the Xisha Archipelago. Master Dissertation, Lanzhou University, China (in Chinese with English abstract).

44. Phalan BT, Northrup JM, Yang Z, Deal RL, Rousseau JS, Spies TA, Betts MG. Impacts of the Northwest Forest Plan on forest composition and bird populations. Proc Natl Acad Sci USA. 2019;116(8):3322-7. https://doi.org/ 10.1073/pnas.1813072116.

45. R Core Team (2017) R: a language and environment for statistical computing. R Foundation for Statistical Computing, Vienna, Austria. https:// www.r-project.org. Accessed 5 Dec 2020

46. Ren $\mathrm{H}$, Jian $\mathrm{S}$, Zhang $\mathrm{Q}$, Wang F, Shen T, Wang J. Plants and vegetation on South China Sea Islands. Ecol Environ Sci. 2017;26:1639-48. https://doi. org/10.16258/j.cnki.1674-5906.2017.10.001 (in Chinese with English abstract).
47. Richards DR, Friess DA. Rates and drivers of mangrove deforestation in Southeast Asia, 2000-2012. Proc Natl Acad Sci USA. 2015;113:344-9. https://doi.org/10.1073/pnas.1510272113.

48. Shu Z, Ling G. The survey report of the island land utilizes in Hainan Province. In: Lu F, Xiong S, Liu S, editors. Resource, synthetically special investigations report collections of Hainan Province. Beijing: Maritine Press; 1999. p. 24-35 (in Chinese).

49. Sodhi NS, Wilcove DS, Lee TM, Sekercioglu CH, Subaraj R, Bernard H, Yong DL, Lim SL, Prawiradilaga DM, Brook BW. Deforestation and avian extinction on tropical landbridge islands. Conserv Biol. 2010;24:1290-8. https:// doi.org/10.1111/j.1523-1739.2010.01495.x.

50. Solé RV, Montoya JM. Complexity and fragility in ecological networks. Proc Biol Sci. 2001;268:2039-45. https://doi.org/10.1098/rspb.2001.1767.

51. Staniczenko PPA, Lewis OT, Jones NS, Reed-Tsochas F. Structural dynamics and robustness of food webs. Ecol Lett. 2010;13:891-9. https://doi.org/10. 1111/j.1461-0248.2010.01485.x.

52. Starling-Windhof A, Massaro M, Briskie JV. Differential effects of exotic predator-control on nest success of native and introduced birds in New Zealand. Biol Invasions. 2011;13:1021-8. https://doi.org/10.1007/ s10530-010-9886-5.

53. Traveset A, Olesen JM, Nogales M, Vargas P, Jaramillo P, Antolín E, Trigo MM, Heleno R. Bird-flower visitation networks in the Galápagos unveil a widespread interaction release. Nat Commun. 2015;6:6376. https://doi. org/10.1038/ncomms7376.

54. Triantis KA, Borges PAV, Ladle RJ, Hortal J, Cardoso P, Gaspar C, Dinis F, Mendonca E, Silveira LMA, Gabriel R, Melo C, Santos AMC, Amorim IR, Ribeiro SP, Serrano ARM, Quartau JA, Whittaker RJ. Extinction debt on oceanic islands. Ecography. 2010;33:285-94. https://doi.org/10.1111/j. 1600-0587.2010.06203.x.

55. Whitaker FF, Smart PL. Climatic control of hydraulic conductivity of Bahamian limestones. Groundwater. 2010;35:859-68. https://doi.org/10.1111/j. 1745-6584.1997.tb00154.x.

56. Whittaker RJ, Fernández-Palacios JM. Island biogeography: ecology, evolution, and conservation. 2nd ed. Oxford: Oxford University Press; 2007.

57. Whittaker RJ, Triantis KA, Ladle RJ. A general dynamic theory of oceanic island biogeography. J Biogeogr. 2008;35:977-94. https://doi.org/10. 1111/j.1365-2699.2008.01892.x.

58. Wilson SD, Belcher JW. Plant and bird communities of native prairie and introduced Eurasian vegetation in Manitoba, Canada. Conserv Biol. 1989;3:39-44. https://doi.org/10.1111/j.1523-1739.1989.tb00222.x.

59. Xu L, Liu X, Sun L, Yan H, Luo Y, Huang J. Geochemical evidence for the development of coral island ecosystem in the Xisha Archipelago of South China Sea from four ornithogenic sediment profiles. Chem Geol. 2011;286:135-45. https://doi.org/10.1016/j.chemgeo.2011.04.015.

60. Zedler JB, Kercher S. Wetland resources: status, trends, ecosystem services, and restorability. Annu Rev Environ Resour. 2005;30:39-74. https:// doi.org/10.1146/annurev.energy.30.050504.144248.

61. Zheng G. A checklist on the classification and distribution of the birds of China (in Chinese). Beijing: Science Forestry Publishing House; 2017. (in Chinese).

\section{Publisher's Note}

Springer Nature remains neutral with regard to jurisdictional claims in published maps and institutional affiliations. 